\title{
ECOLOGICAL AND ECONOMIC STATE OF REGIONS: IMPROVEMENT OF METHODOLOGY AND METHODS OF ASSESSMENT ${ }^{1}$
}

\author{
Irina D. Anikina \\ Volgograd State University, Volgograd, Russian Federation \\ Andrey A. Anikin \\ Volgograd State University, Volgograd, Russian Federation
}

\begin{abstract}
Sustainable environmental and economic development of economic actors requires "ecological" thinking, which involves the adoption of economic actors responsible for the consequences of the impacts of production activities on the environment. Taking into account both the efficiency of economic activities and changes in the environmental situation is the main step for the development of monitoring of the ecological and economic condition of the territories. The aim of the study is to develop the methodology for assessing the ecological and economic development of regions on the basis of the concept of sustainable development by clarifying the principles of assessment and methods of decoupling analysis. The paper uses the method of decoupling analysis refined by the authors by means of six sectors that characterize different degrees of the ecological and economic state of the regions. The paper presents the results of the decoupling analysis of 80 Russian regions for the period 2010-2016 according to the method proposed by the authors. The authors analyze indicators of GRP and emissions of pollutants from stationary sources. The article substantiates the conclusion that the decoupling effect is stable in the majority of Russian regions relative to 2010, while it reveals a negative effect of crises on the ecological-economic condition of the region manifested in 2015 and 2016. The results of the analysis contribute to a better understanding of the nature of the decoupling effect and can be used for forming a monitoring system of environmental-economic status areas.
\end{abstract}

Key words: principles of assessment of ecological and economic state of a region, "green" economy, "decoupling" effect, environmental problems, socio-economic development of regions.

Citation. Anikina I.D., Anikin A.A. Ecological and Economic State of Regions: Improvement of Methodology and Methods of Assessment. Journal of Volgograd State University. Economics, 2019, vol. 21, no. 4, pp. 141-151. (in Russian). DOI: https://doi.org/10.15688/ek.jvolsu.2019.4.14

\section{ЭКОЛОГО-ЭКОНОМИЧЕСКОЕ СОСТОЯНИЕ РЕГИОНОВ: СОВЕРШЕНСТВОВАНИЕ МЕТОДОЛОГИИ И МЕТОДИКИ ОЦЕНКИ ${ }^{1}$}

\author{
Ирина Дмитриевна Аникина \\ Волгоградский государственный университет, г. Волгоград, Российская Федерация \\ Андрей Андреевич Аникин \\ Волгоградский государственный университет, г. Волгоград, Российская Федерация
}

Аннотация. Устойчивое эколого-экономическое развитие экономических субъектов требует «экологи-
ческого» мышления, которое предполагает принятие экономическими субъектами ответственности за по-
следствия воздействий производственной деятельности на окружающую среду обитания. Учет одновремен-
но эффективности хозяйственной деятельности и изменения экологической обстановки является основой
для разработки мониторинга эколого-экономического состояния территорий. Целью исследования явилось 
развитие методологии оценки эколого-экономического развития регионов на основе концепции устойчивого развития посредством уточнения принципов оценки и методики декаплинг-анализа. В работе использовался метод декаплинг-анализа, уточненный авторами посредством выделения шести секторов, характеризующих различную степень эколого-экономического состояния регионов. Приведены результаты декаплинганализа 80 российских регионов за период 2010-2016 гг. по предложенной авторами методике. Анализируются показатели ВРП и выбросов загрязняющих веществ от стационарных источников. Обосновывается вывод о стабильном эффекте «декаплинга» в большинстве российских регионов по отношению к 2010 г., при этом выявлено негативное влияние кризисов на эколого-экономическое состояние регионов, проявившееся в 2015 и 2016 годах. Результаты анализа способствуют более глубокому пониманию сущности эффекта «декаплинга» и могут быть использованы для формирования системы мониторинга эколого-экономического состояния регионов.

Ключевые слова: принципы оценки эколого-экономического состояния региона, «зеленая» экономика, эффект «декаплинга», экологические проблемы, социально-экономическое развитие регионов.

Цитирование. Аникина И. Д., Аникин А. А. Эколого-экономическое состояние регионов: совершенствование методологии и методики оценки // Вестник Волгоградского государственного университета. Экономика. -2019. - Т. 21, № 4. - C. 141-151. - DOI: https://doi.org/10.15688/ek.jvolsu.2019.4.14

\section{Введение}

Важность рассмотрения экологических проблем как отдельных регионов, так и мира в целом, не вызывает сомнения, поскольку именно качество окружающей среды формирует качество жизни населения. Внимание к проблемам экологии, их взаимосвязь и взаимозависимость с экономическими проблемами привели к формированию концепции устойчивого экономического роста и разработке теории «зеленого роста». Данные концепции и теория в настоящее время активно обсуждаются и внедряются в практику мировой и региональных экономик. Они являются основой для принятия политических, экономических, финансовых, технических решений как на межгосударственном уровне, на уровне отдельных государств, регионов, компаний, каждого человека в отдельности. Принципы «зеленой» экономики были представлены Программой OОН по окружающей среде (ЮНЕП - United Nations Environment Programme) в докладе «Глобальный зеленый новый курс» [Глобальный зеленый новый курс..., 2009]. 2009 г. был годом мирового финансового кризиса и именно он привел к осознанию невозможности дальнейшего развития по модели докризисного экономического роста. В программе были определены ключевые направления и принципы инвестирования в посткризисной экономике, такие как стимулирование инвестиций в безотходные технологии, регенерация инфраструктуры окружающей среды (леса, водные ресурсы, воздух, почвы). Устойчивый экономический рост должен обеспечиваться за счет воссоздания и развития «зеленой» инфраструктуры и повышения качества жизни населения. Таким образом, концепция устойчивого экономического развития связывает повышение благосостояния людей со снижением экологических рисков, декларирует экономический рост при одновременном улучшении (или неухудшении) состояния окружающей среды.

Концепция устойчивого экономического развития явилась ответом на современные глобальные проблемы и вызовы, стоящие перед человечеством. Глобальные проблемы это проблемы, от которых зависит выживание и развитие человечества в целом, они в значительной степени сформированы современной системой ценностей человека, его поведенческими стереотипами, культурными паттернами; данные проблемы затрагивают каждого человека на планете и требуют согласованных решений всего общества.

Для характеристики устойчивого развития разрабатываются системы индикаторов, которые позволяют дать адекватную оценку используемым средствам и уровню достижения целей, проводить эффективный мониторинг и осуществлять управление экологоэкономической политикой регионов. В резолюции, принятой Генеральной ассамблеей ООН 25 сентября 2015 г. «Повестка дня в области устойчивого развития на период до 2030 года», поставлены 17 целей и 169 задач в области устойчивого развития. В докумен- 
те подчеркивается важность не только экономического развития, но и экологического устойчивого развития: «Мы преисполнены решимости обеспечить, чтобы все люди могли жить в условиях процветания и благополучия и чтобы экономический, социальный и технический прогресс продолжался в гармонии с природой» [Резолюция..., 2015]. Постановка целей и задач требует разработки индикаторов устойчивого развития для мониторинга и оценки эффективности управленческих решений.

Важность разработки индикаторов устойчивого развития отмечает проф. С.Н. Бобылев (МГУ): «Комплекс таких индикаторов - показателей и критериев - должен играть ключевую роль в описании (диагностике) состояния системы «природа - хозяйство население... Пока ни о полноте комплекса индикаторов устойчивого развития, ни о достаточной точности их исчисления говорить рано...» [Бобылев и др., 2015]. В настоящее время наиболее широко известны такие экономические индикаторы на уровне макро- и мезоэкономики, как ВВП (валовой внутренний продукт), ВНД (валовой национальный продукт), ВРП (валовой региональный продукт) и т. п. Данные индикаторы подвергаются критике со стороны многих экспертов ввиду того, что они отражают исключительно экономические аспекты жизни, но не действительную удовлетворенность индивидов жизнью. Кроме того, данные показатели не учитывают, что производство и потребление могут приводить (и приводили) к значительному ухудшению природной среды обитания человека.

Для учета не только экономического развития, но одновременно и проводимой государствами экологической политики, разработаны различные подходы. Они включают два направления: 1) построение отдельных индикаторов и / или системы индикаторов, которые показывают различные аспекты устойчивого развития территорий; 2) интегральные показатели эффективности социально-экономического развития, которые включают оценку влияния деятельности человека на окружающую среду. Рассмотрим их более подробно:

1. Отдельные индикаторы и / или системы индикаторов устойчивого развития территорий.
1.1. Показатели ресурсоемкости. Данные показатели рассчитываются как удельные затраты на единицу конечного результата (конечной продукции (ТП), ВВП, ВРП): удельная энергоемкость, удельная водоемкость, удельная землеемкость.

1.2. Показатели интенсивности загрязнений. Показатели рассчитываются аналогично предыдущим как удельные величины: удельные величины различных загрязнений, отходов, газов.

Такие показатели необходимо сравнивать в динамике и с другими странами, регионами.

2. Системы показателей (индикаторы) устойчивого развития.

Индикаторы устойчивого развития разрабатываются различными организациями при поддержке ООН. Многие страны включили в свои статистические показатели индикаторы устойчивого развития. Среди наиболее известных такие, как:

2.1. Индекс человеческого развития (Индекс развития человеческого потенциала);

2.2. Индекс скорректированных чистых накоплений (Всемирный банк);

2.3. Индекс счастья;

2.4. Экологический след (ecological footprint) (WWF);

2.5. Индекс «живой планеты» (living planet index) (WWF);

2.6. Цели устойчивого развития (ЦУР).

Данные альтернативные показатели, как считают их разработчики, лучше показывают реальное состояние развития индивидов, общества и качества жизни в разных странах. Показатели и индексы рассчитываются на основе как статистических данных, так и экспертных оценок. Имеются регулярные оценки по странам и регионам, что позволяет провести сравнение и оценить усилия отдельных государств в борьбе с глобальными экологическими проблемами. Отметим, что расчет показателей достаточно сложен и трудоемок.

Для оценки эколого-экономического развития территорий наибольшее признание в российской практике получил показатель скорректированных чистых накоплений (Adjusted Net Saving), на основе которого исследователями [Эколого-экономический индекс регионов..., 2012] предложен показатель «эколого- 
экономический индекс регионов РФ». Показатель был рассчитан для российских регионов за 2012 г., что сделало возможным проанализировать данные между регионами и выявить региональную специфику, но отсутствие расчетов в динамике не позволило оценить эффективность эколого-экономического развития регионов.

Bсе изученные индикаторы и системы индикаторов не позволяют сделать однозначные выводы о взаимозависимости экономического развития регионов и территорий и росте (или уменьшении) экологических угроз и дать оценку эколого-экономических рисков регионов. Данный подход важен, по нашему мнению: 1) для инвесторов, реализующих проекты экологической направленности в регионах: с точки зрения современной концепции устойчивого роста и «зеленой экономики» им важно знать, насколько экономическая эффективность соотносится с изменением экологической нагрузки в регионе; 2) для региональных органов власти и общественности: как инструмент для оценки усилий и эффективности регионов в области «зеленого» развития, которое предполагает необходимость экономического роста при сокращении вредного воздействия на окружающую среду. С целью решения данных проблем автором была предложена методика декаплинг-анализа, позволяющая оценить эколого-экономическое развитие регионов и ранжировать их по рейтингу «эколого-экономической привлекательности».

Для анализа эколого-экономического состояния регионов в мировой практике используется индекс декаплинга [System of EnvironmentEcomonic Accounting..., 2012]. Он характеризует эффект «декаплинга», то есть «расщепление», «разъединение» темпов роста показателей экономического роста (ВВП, ВРП) и темпов роста потребления природных ресурсов и отходов производства и потребления. Наличие эффекта «декаплинга» является необходимым условием устойчивого развития регионов. Оценка эффекта «декаплинга» в региональной экономике позволит ранжировать регионы по уровню эколого-экономического развития, сделать выводы об эффективности эколого-экономической политики регионов.

О важности и необходимости эффекта «декаплинга» для российской экономики в со- временных условиях говорит в своих выступлениях и докладах С.Н. Бобылев - д-р экон. наук, зав. кафедрой экономики природопользования МГУ, профессор, заслуженный деятель науки РФ [Устойчивое развитие..., 2015 , с. 57]. В исследованиях А.Д. Думнова, Д.А. Борискина, Н.Г. Рыбальского отмечается упрощенный подход к выводам, которые можно сделать на основе традиционного декаплинг-анализа, а также говорится о том, что «осознание показателей декаплинга... со стороны отдельных ученых и специалистов в России серьезно задержалось» [Думнов и др., 2017, с. 45]. Анализ эффекта «декаплинга» по ряду российских регионов и отраслей был представлен в работах исследователей: А.О. Акулова, С.Н. Кириллова и коллектива ученых, В.П. Самариной, Г.И. Шкиперова, Е.Ю. Яковлевой, Н.Н. Яшаловой [Акулов, 2013; Кириллов и др., 2017; Самарина, 2015; Шкиперова, 2014; Яковлева, 2016; Яшалова, 2014]. При общеметодологическом единстве к пониманию сущности эффекта «декаплинга» применяемые на практике методики расчета данного эффекта различны в отношении используемых показателей и формул расчета. Так, исследователи используют при анализе следующие показатели: экономические - валовой региональный продукт, объем промышленного производства, рост благосостояния населения; показатели антропогенного воздействия на окружающую среду это такие индикаторы, как показатели загрязнения окружающей среды; оценку ресурсосбережения проводят, анализируя специфические отраслевые показатели, например, для горнодобывающих отраслей: объемы добычи руды, площадь отторгаемых земель, площадь земель с нарушенным водным балансом и т. п., а также показатели экологоэкономического учета.

Исследователи отмечают актуальность анализа эффекта «декаплинга»: «использование коэффициента декаплинга для оценки устойчивости развития открывает в дальнейшем перспективы для работ методического характеpa: предложения по классификации показателей декаплинга для разных видов природопользования будут способствовать формированию методики оценки устойчивости на региональном уровне» [Кириллов и др., 2017, с. 133]. 
Для исследования авторы уточнили цели, принципы и предложили модель углубленного декаплинг-анализа.

Целями разработки индикаторов социально-экономического развития регионов являются:

1. Принятие управленческих решений:

- при разработке стратегий, программ планов развития регионов;

- при прогнозировании ожидаемых эколого-экономических эффектов;

- при мониторинге реализации региональных стратегий, программ, планов;

- при оценке и корректировке стратегий, планов и программ.

2. Анализ данных:

- для сравнения, оценки данных на уровне макро-, мезо- и микроэкономики (стран, регионов, отраслей, компаний);

- для выявления тенденций эколого-экономического развития регионов.

3. Информирование всех стейкхолдеров (органы власти государства и регионов, общественность, инвесторы, организации) об эколого-экономическом состоянии регионов для принятия различных управленческих решений.

Принципами разработки индикаторов эколого-экономического развития регионов являются следующие:

1. Принцип динамики: индикаторы должны обеспечивать возможность анализа динамики изменений, мониторинга эффективности деятельности, оценку направленности изменений (негативное или позитивное).

2. Принцип информированности (полезности): индикаторы должны обеспечивать обоснованную информацию для принятия управленческих решений и отражать информацию о существенных эколого-экономических проблемах.

3. Принцип учета интересов стейкхолдеров: индикаторы должны быть понятными для стейкхолдеров и отражать информацию, полезную для принятия решений многими экономическими субъектами.

4. Принщип достоверности: индикаторы должны отражать существенную информацию, полезную для принятия решений; затраты на получение и обработку информации необходимо соотносить с полезностью их ис- пользования, данные для расчета индикаторов должны обеспечивать достоверность, точность, надежность, необходимую частоту расчетов;

Выделим дополнительно к принципам следующие критерии, которым должны удовлетворять индикаторы: количественная оценка; использование данных официальной статистики; отсутствие экспертных оценочных суждений; возможность оценки в динамике, по уровням экономической системы (макро-, мезо-, микроуровни), по секторам экономики; конечное число индикаторов.

\section{Метод углубленного декаплинг-анализа}

Эффект «декаплинга» оценивается на основе индекса декаплинга (DI) за определенный период времени (как правило, год) по формуле (1) [Яковлева, 2016]:

$$
D I=T_{R} / T_{Y}
$$

где $T_{R}$ - относительное изменение (коэффициент роста) потребляемого ресурса или выброса загрязнения за определенный период; $T_{Y}$ - относительное изменение (коэффициент роста) результирующего показателя (как правило ВВП, ВРП и т. п.) за аналогичный период; $D I-$ индекс декаплинга, выраженный в относительных единицах; при $D I>1,0$ - эффект «декаплинга» отсутствует потребление ресурсов или загрязнение окружающей среды происходит более быстрыми темпами, чем экономический рост, происходит интенсивное загрязнение окружающей среды; при $D I=1,0$ темпы экономического роста и загрязнения окружающей среды одинаковы; при $1,0<D I$ наблюдается эффект «декаплинга» - темпы экономического роста выше, чем темпы загрязнения окружающей среды.

Индекс декаплинга, рассчитанный по формуле (1), дает возможность оценить наличие эффекта «декаплинга», но отсутствует возможность более глубоких выводов об эколого-экономическом состоянии региона. Авторами предлагается модель анализа эффекта «декаплинга», основанная на сопоставлении коэффициентов прироста потребляемых ресурсов и / или загрязнений и показателями экономического роста. Скорректированный индекс декаплинга в модели рассчитывается по следующей формуле (2): 


$$
D I^{\prime}=T_{R}^{\prime}-T_{Y}^{\prime}
$$

где $D I^{\prime}$ - скорректированный индекс декаплинга, выраженный в относительных единицах; $T_{R}{ }^{\prime}$ - коэффициент прироста потребляемого ресурса или выброса загрязнения за определенный период, отн. ед.; $T_{Y}^{\prime}$ - коэффициент прироста результирующего показателя за аналогичный период, отн. ед.

Оценивая прирост или уменьшение показателей и скорость прироста показателей между собой, можно выделить шесть секторов, характеризующих различную степень эффективности эколого-экономического состояния региона.

Сектор I: $T_{R}^{\prime}(-)<T_{Y}^{\prime}(+), D I^{\prime}<0$. Наличие эффекта «абсолютного декаплинга»: наблюдается снижение выбросов в окружающую среду и рост экономических показателей эффективности (чаще всего в этом качестве выступают показатели ВВП, ВРП). Это наиболее благоприятная ситуация для экономики региона, характеризующаяся снижением экологической нагрузки в регионе при одновременном экономическом росте, устойчивое развитие региона.

Сектор II: $T_{R}{ }^{\prime}(+; 0,0)<T_{Y}^{\prime}(+), D I^{\prime}<0,0$ либо $=0,0$. Наличие эффекта «относительного декаплинга»: растут выбросы в окружающую среду и экономические показатели, но прирост выбросов меньше прироста экономических показателей. «Нормальный экономический рост». Нормальная ситуация, рост эффективности экономики региона сопровождается ростом экологических издержек, растет негативное воздействие на окружающую среду, но индекс декаплинга остается отрицательной величиной, что говорит об устойчивом развитии региона.

Сектор III: $T_{R}^{\prime}(-; 0,0)>T_{Y}^{\prime}(-; 0,0), D I^{\prime}<0,0$ либо $=0,0$. Наличие эффекта «относительного декаплинга»: снижаются выбросы и антропогенная нагрузка на окружающую среду и экономические показатели. Ситуация характеризуется снижением экологической нагрузки на регион при одновременном снижении ВРП, но экологическая нагрузка снижается быстрее экономических результатов. Такая ситуация возможна в условиях реструктуризации производств, перехода на новые инновационные технологии.

Сектор IV: $T_{R}^{\prime}(+)>T_{Y}^{\prime}(+), D I^{\prime}>0$. Эффект «декаплинга» отсутствует: темпы при- роста выбросов больше темпов прироста экономических показателей. Замедление эффективности эколого-экономического развития региона. «Бурый» экономический рост. Происходит ускоренная нагрузка на экологическое состояние региона, но наблюдается и экономический рост. Необходимо уделять внимание поддержке «зеленых» технологий и проектов.

Сектор V: $T_{R}^{\prime}(-)<T_{Y}^{\prime}(-), D I^{\prime}>0$. Эффект «декаплинга» отсутствует: темпы прироста выбросов отрицательны и меньше темпов снижения экономических показателей. Для данной ситуации характерно снижение экологической нагрузки при одновременно большем ухудшении показателей эффективности региональной экономики.

Сектор VI: $T_{R}^{\prime}(+)>T_{Y}^{\prime}(-), D I^{\prime}>0$. Эффект «декаплинга» отсутствует: положительные темпы прироста выбросов в окружающую среду при отрицательных темпах прироста экономических показателей. Наихудшая, кризисная ситуация, при которой рост нагрузки на экологию региона сопровождается ухудшением экономической ситуации.

Предложенная модель позволяет выделить шесть секторов, характеризующих качественно различные состояния эколого-экономической ситуации, что позволяет более объективно оценить эффективность региональных управленческих решений в сфере эколого-экономической политики.

Адаптация методики углубленного декаплинг-анализа на примере 80 российских регионов. В качестве исходных данных использовались данные Росстата по регионам за 2010-2016 гг. (ЕМИС), такие как: выбросы загрязняющих веществ от стационарных источников, тыс. тонн; индексы физического объема валового регионального продукта на душу населения; численность населения, тыс. человек. Авторами был проведен анализ и рассчитаны индексы декаплинга по российским регионам по модели углубленного декаплиг-анализа (2) по данным прироста показателей на душу населения. Расчеты велись по двум вариантам: в первом варианте использовались базисные индексы по отношению к 2010 г., во втором варианте рассчитывались цепные индексы. Результаты анализа представлены в таблице 1. 
И.Д. Аникина, А.А. Аникин. Эколого-экономическое состояние регионов

Таблица 1

Структура регионов по секторам методики декаплинг-анализа

за период 2011-2016 гг.

\begin{tabular}{|c|c|c|c|c|c|c|c|c|c|c|c|c|}
\hline Год & \multicolumn{2}{|c|}{2011} & \multicolumn{2}{|c|}{2012} & \multicolumn{2}{|c|}{2013} & \multicolumn{2}{|c|}{2014} & \multicolumn{2}{|c|}{2015} & \multicolumn{2}{|c|}{2016} \\
\hline Показатели & $\mathrm{g}$ & $\%$ & $\mathrm{~g}$ & $\%$ & $\mathrm{~g}$ & $\%$ & $\mathrm{~g}$ & $\%$ & $\mathrm{~g}$ & $\%$ & $\mathrm{~g}$ & $\%$ \\
\hline \multicolumn{13}{|c|}{ Вариант 1} \\
\hline 1 & 39 & 48,75 & 34 & 42,5 & 38 & 47,50 & 43 & 53,75 & 45 & 56,25 & 45 & 56,25 \\
\hline 2 & 21 & 26,25 & 24 & 30,00 & 20 & 25,00 & 10 & 12,50 & 13 & 16,25 & 13 & 16,25 \\
\hline 3 & 0 & 0,00 & 2 & 2,50 & 2 & 0,00 & 5 & 6,25 & 5 & 6,25 & 5 & 6,25 \\
\hline Всего 1-3 & 60 & 75,00 & 60 & 75,00 & 60 & 75,00 & 58 & 72,50 & 63 & 78,75 & 59 & 73,75 \\
\hline 4 & 19 & 23,75 & 18 & 22,5 & 16 & 23,75 & 21 & 26,25 & 16 & 20 & 16 & 20 \\
\hline 5 & 0 & 0 & 1 & 1,25 & 1 & 0 & 0 & 0 & 1 & 1,25 & 1 & 1,25 \\
\hline 6 & 1 & 1,25 & 1 & 1,25 & 3 & 1,25 & 1 & 1,25 & 0 & 0 & 0 & 0 \\
\hline Всего 4-6 & 20 & 25,00 & 20 & 25,00 & 20 & 25,00 & 22 & 27,50 & 17 & 21,25 & 21 & 21,25 \\
\hline Итого & 80 & 100 & 80 & 100 & 80 & 100 & 80 & 100 & 80 & 100 & 80 & 100 \\
\hline \multicolumn{13}{|c|}{ Вариант 2} \\
\hline 1 & 39 & 48,75 & 26 & 32,5 & 35 & 45,00 & 37 & 46,25 & 16 & 20,00 & 22 & 27,50 \\
\hline 2 & 21 & 26,25 & 19 & 23,75 & 7 & 8,75 & 3 & 3,75 & 3 & 3,75 & 3 & 3,75 \\
\hline 3 & 0 & 0,00 & 5 & 6,25 & 6 & 7,50 & 11 & 13,75 & 23 & 28.75 & 8 & 10,00 \\
\hline Всего 1-3 & 60 & 75,00 & 50 & 62,50 & 49 & 75,00 & 51 & 75,00 & 42 & 52,50 & 33 & 41,25 \\
\hline 4 & 19 & 23,75 & 26 & 32,5 & 21 & 23,75 & 23 & 28,75 & 17 & 21,25 & 27 & 33,75 \\
\hline 5 & 0 & 0,00 & 2 & 2,50 & 2 & 2,50 & 1 & 1,25 & 3 & 3,75 & 2 & 2,50 \\
\hline 6 & 1 & 1,25 & 2 & 2,5 & 9 & 1,25 & 6 & 7,50 & 18 & 22,50 & 18 & 22,50 \\
\hline Всего 4-6 & 20 & 25,00 & 30 & 37,50 & 31 & 25,00 & 29 & 37,50 & 38 & 47,50 & 47 & 58,75 \\
\hline Итого & 80 & 100 & 80 & 100 & 80 & 100 & 80 & 100 & 80 & 100 & 80 & 100 \\
\hline
\end{tabular}

Примечание. Рассчитано и составлено авторами. $1,2, \ldots, 6$ - номер сектора в модели декаплинг-анализа; $\mathrm{g}$ - количество регионов в секторе модели декаплинг-анализа; \% - процент регионов в секторе модели декаплинг-анализа.

Анализ позволяет сделать следующие выводы: по сравнению с 2010 г. наблюдается устойчивый эффект «декаплинга» в российских регионах: количество регионов с эффектом «декаплинга» колеблется около 75 \% за анализируемый период, при этом число регионов с абсолютным эффектом «декаплинга» составляет в среднем 40, то есть практически $50 \%$ российских регионов. Из оставшихся регионов около половины (в среднем 18 регионов) находятся в секторе «бурого роста», то есть наблюдается экономический рост, но при большей нагрузке на окружающую среду. Но, если изменить подход к выбору точки отсчета (базисного периода) и рассмотреть изменение цепных показателей, что предполагает анализ стремления к достижению ежегодной эффективности, то увидим негативные тенденции. Так, за анализируемый период (шесть лет) имеется тенденция к ухудшению эколого-экономического состояния российских регионов в последние два года (2015, 2016). Так, в 2011 г. в 75,00 \% регионов наблюдался эффект «декаплинга», при этом в 48,75 \% отмечался абсолютный эффект «декаплинга»наилучшая ситуация, которая характеризуется экономическим ростом при снижении антропогенной нагрузки на окружающую среду. В следующие периоды наблюдалась тенденция к снижению числа регионов, имеющих эффект «декаплинга»: 2012 г. - количество регионов с эффектом «декаплинга» составило $62,50 \%$, в 2013 г. - 61,25\%, в 2014 г. - 75,00 \%, далее отмечается резкий спад: в 2015 г. - 52,50\%, в 2016 $41,25 \%$. При этом снижалось «качество» эфффекта «декаплинга»: количество регионов с абсолютным эффектом «декаплинга» уменьшилось в 1,77 раза (с 48,75 \% до 27,5 \%).

Увеличилось число регионов, эколого-экономическое состояние которых можно охарактеризовать как «бурый» рост. Так, в 2011 г. «бурый» рост был характерен для 19 регионов $(23,75 \%)$, в 2012 г. - для 26 регионов $(32,5 \%)$, в 2013 г. - для 20 регионов (25,00 \%); в 2014 г. для 23 регионов $(28,75 \%)$; в 2015 г. - для 16 регионов $(20,00 \%)$; в 2016 г. - для 27 регионов $(33,75 \%)$.

Что касается наихудшей ситуации в декаплинг-модели, а именно снижения экономических показателей при увеличении антропогенной нагрузки на окружающую среду, то можно отме- 
тить, что на протяжении исследуемого периода отчетливо видна отрицательная динамика: в 2011 г. только для одного региона была характерна такая ситуация, в 2012 г. - для двух регионов, в 2013 г. - уже для девяти, в 2014 г. - пять регионов оказались в данном секторе, в 2015 г. $19(23,75 \%)$, в 2016 г. - 18 регионов $(22,5 \%)$.

Можно сделать вывод, что сложная экономическая ситуация для российской экономики в 2015-2016 гг. негативно отразилась не только на благополучии населения, но и привела к ухудшению окружающей среды, при этом по сравнению с 2010 г. ситуация остается стабильной. Такая ситуация ожидаема, поскольку экономические процессы характеризуются инерционностью в своем развитии. Это позволяет прийти к заключению о необ- ходимости исследования эколого-экономических процессов в динамике и учете фаз экономического цикла, подводя итоги эффективности эколого-экономической политики регионов.

Сравнивая состав регионов по секторам модели декаплинг-анализа в 2011 и в 2016 гг. (табл. 2) можно сделать вывод о высокой вариативности: абсолютный эффект «декаплинга» (1-й сектор) сохранили 61,5\% регионов, то есть 38,5 \% ухудшили свое эколого-экономическое состояние. Еще большие изменения в составе регионов произошли в остальных секторах: во втором секторе осталось 23,8 \% в 2016 г. по сравнению с 2011 г., в четвертом секторе («бурый» рост) характерен для 42,1\% (8 из 19 регионов), Чукотский автономный округ поднялся из шестого сектора в пятый.

Таблица 2

\section{Структура регионов по секторам декаплинг-анализа}

\begin{tabular}{|c|c|c|c|}
\hline Сектор & Регионы & $\mathrm{g}$ & $\%$ \\
\hline \multicolumn{4}{|c|}{2016} \\
\hline 1 & $\begin{array}{l}\text { Белгородская область, Владимирская область, Воронежская область, Костромская } \\
\text { область, Курская область, Липецкая область, Орловская область, Рязанская область, } \\
\text { Тульская область, Архангельская область, Вологодская область, Калининградская } \\
\text { область, Мурманская область, Волгоградская область, Республика Калмыкия, Рос- } \\
\text { товская область, Республика Дагестан, Карачаево-Черкесская Республика, Респуб- } \\
\text { лика Северная Осетия-Алания, Чеченская Республика, Чувашская Республика, } \\
\text { Пермский край, Нижегородская область, Оренбургская область, Самарская область, } \\
\text { Ульяновская область, Курганская область, Свердловская область, Челябинская об- } \\
\text { ласть, Республика Тыва, Республика Хакасия, Забайкальский край, Красноярский } \\
\text { край, Новосибирская область, Омская область, Томская область, Камчатский край, } \\
\text { Хабаровский край, Сахалинская область, Чукотский автономный округ }\end{array}$ & 40 & 50,00 \\
\hline 2 & $\begin{array}{l}\text { Брянская область, Тамбовская область, Тверская область, Ярославская область, Рес- } \\
\text { публика Коми, Ленинградская область, Новгородская область, Астраханская об- } \\
\text { ласть, Республика Марий Эл, Республика Мордовия, Кировская область, Саратов- } \\
\text { ская область, Алтайский край, Иркутская область }\end{array}$ & 14 & 17,50 \\
\hline 3 & $\begin{array}{l}\text { Ивановская область, г. Москва, Тюменская область, Приморский край, Еврейская } \\
\text { автономная область }\end{array}$ & 5 & 6,25 \\
\hline 4 & $\begin{array}{l}\text { Калужская область, Московская область, Смоленская область, Республика Карелия, } \\
\text { Псковская область, Санкт-Петербург, Республика Адыгея, Краснодарский край, Респуб- } \\
\text { лика Ингушетия, Кабардино-Балкарская Республика, Ставропольский край, Республика } \\
\text { Башкортостан, Республика Татарстан, Удмуртская Республика, Пензенская область, Рес- } \\
\text { публика Алтай, Республика Саха (Якутия), Амурская область, Магаданская область }\end{array}$ & 19 & 23,75 \\
\hline 5 & Республика Бурятия, Кемеровская область & 2 & 2,50 \\
\hline 6 & - & 0 & 0,00 \\
\hline \multicolumn{4}{|c|}{2011} \\
\hline 1 & $\begin{array}{l}\text { Воронежская область, Костромская область, Липецкая область, Московская об- } \\
\text { ласть, Рязанская область, Ярославская область, г. Москва, Республика Карелия, Ар- } \\
\text { хангельская область, Вологодская область, Калининградская область, Ленинград- } \\
\text { ская область, Мурманская область, Новгородская область, Волгоградская область, } \\
\text { Ростовская область, Республика Дагестан, Республика Ингушетия, Кабардино- } \\
\text { Балкарская Республика, Республика Северная Осетия-Алания, Чеченская Республи- } \\
\text { ка, Республика Марий Эл, Чувашская Республика, Кировская область, Нижегород- } \\
\text { ская область, Самарская область, Курганская область, Свердловская область, Челя- } \\
\text { бинская область, Республика Бурятия, Республика Тыва, Республика Хакасия, Ал- } \\
\text { тайский край, Забайкальский край, Кемеровская область, Республика Саха (Якутия), } \\
\text { Камчатский край, Хабаровский край, Сахалинская область }\end{array}$ & 39 & 48,75 \\
\hline
\end{tabular}


Окончание таблицы 2

\begin{tabular}{|c|c|c|c|}
\hline Сектор & Регионы & $\mathrm{g}$ & $\%$ \\
\hline \multicolumn{4}{|c|}{2011} \\
\hline 2 & $\begin{array}{l}\text { Белгородская область, Брянская область, Владимирская область, Ивановская об- } \\
\text { ласть, Калужская область, Курская область, Орловская область, Смоленская об- } \\
\text { ласть, Тамбовская область, Астраханская область, Республика Калмыкия, Ставро- } \\
\text { польский край, Республика Башкортостан, Республика Мордовия, Удмуртская Рес- } \\
\text { публика, Красноярский край, Иркутская область, Новосибирская область, Омская } \\
\text { область, Приморский край, Магаданская область }\end{array}$ & 21 & 26,25 \\
\hline 3 & 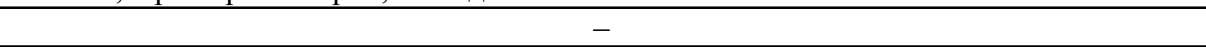 & 0 & 0,00 \\
\hline 4 & $\begin{array}{l}\text { Тверская область, Тульская область, Республика Коми, Псковская область, Санкт- } \\
\text { Петербург, Республика Адыгея, Краснодарский край, Карачаево-Черкесская Рес- } \\
\text { публика, Республика Татарстан, Пермский край, Оренбургская область, Пензенская } \\
\text { область, Саратовская область, Ульяновская область, Тюменская область, Республи- } \\
\text { ка Алтай, Томская область, Амурская область, Еврейская автономная область }\end{array}$ & 19 & 23,75 \\
\hline 5 & - & 0 & 0,00 \\
\hline 6 & Чукотский автономный округ & 1 & 1,25 \\
\hline
\end{tabular}

Примечание. Рассчитано и составлено авторами с использованием базисных индексов, 2010 г. базисный.

\section{Выводы}

Эффективность экономики в настоящее время неотъемлема от учета влияния деятельности человека на окружающую среду. Противоречия экономических и экологических интересов приводят планету к глобальному экологическому кризису. Возросшая значимость экологических проблем диктует необходимость соблюдения принципов устойчивого развития и перехода к «зеленой» экономике. Устойчивый экономический рост должен обеспечиваться за счет воссоздания и развития «зеленой» инфраструктуры и повышения качества жизни населения. К настоящему времени российская экономика не достигла декаплинга - эффекта, при котором экономический рост сопровождается снижением выбросов. Экономические кризисы, наблюдаемые в последнее время, в первую очередь привлекают внимание к политическим, социальным, экологическим проблемам, перенося вектор внимания с экологических проблем. Поиск российскими регионами новых стратегий неразрывно связан с поддержкой и стимулированием эколого-экономического развития, с вниманием к сфере природопользования. Формирование и реализация стратегий экологоэкономического развития регионами требует разработки методов количественной оценки негативного влияния антропогенного воздействия на окружающую среду при сопоставлении с экономическим развитием. В исследо- вании авторами предложена модель углубленного декаплинг-анализа, позволяющая не только оценить наличие или отсутствие эффекта «декаплинга», но и выделить шесть секторов, характеризующих различную степень эффективности эколого-экономического состояния регионов. Авторами проведена апробация модели на примере 80 российских регионов, полученные результаты позволяют сделать вывод о наличии эффекта «декаплинга» в сравнении с 2010 г., но экономические кризисы оказали существенное негативное влияние как на экономическую, так и на экологическую динамику многих российских регионов. Считаем, что разработанную модель возможно применять при мониторинге эколого-экономического состояния регионов для оценки усилий и эффективности регионов по реализации стратегий развития.

\section{ПРИМЕЧАНИЕ}

${ }^{1}$ Исследование выполнено при финансовой поддержке РФФИ в рамках научного проекта № 19-010-00356 «Совершенствование методологии оценки эколого-экономического развития регионов на основе концепции устойчивого развития».

The reported study was funded by RFBR in the framework of research project no. 19-010-00356 "Improvement of Methodology for Assessing the Environmental and Economic Development of Regions Based on the Concept of Sustainable Development". 


\section{СПИСОК ЛИТЕРАТУРЫ}

Акулов, А. О. Эффект декаплинга в индустриальном регионе (на примере Кемеровской области) / О. А. Акулов // Экономические и социальные перемены: факты, тенденции, прогно3. - 2013. - № 4 (28). - С. 177-185.

Глобальный зеленый новый курс. Доклад, март 2009 г. Издано Программой ООН по окружающей среде в рамках Инициативы по зеленой экономике. - Электрон. текстовые дан. - Режим доступа: http://www.unepcom.ru/images/ greeneconomy/greennewdeal.pdf. - Загл. с экрана.

Думнов, А. Д. О некоторых методах макростатистического анализа природопользования и охраны окружающей среды / А. Д. Думнов, Д. А. Борискин, Н. Г. Рыбальский // Век глобализации. - 2017 - № 2. - С. 37-50.

Кириллов, С. Н. Оценка устойчивости развития на региональном уровне: пример Республики Татарстан / С. Н. Кириллов, А. А. Пакина, Н. И. Тульская // Вестник Волгоградского государственного университета. Серия 3, Экономика, Экология. -2017. - №4. - C. 127-137. - DOI: https:/ /doi.org/10.15688/jvolsu3.2017.4.14.

Резолюция, принятая Генеральной ассамблеи ООН 25 сентября 2015 г. - Электрон. текстовые дан. - Режим доступа: https://undocs.org/ru/ A/RES/70/1. - Загл. с экрана.

Самарина, В. П. «Зеленая» экономика России: некоторые вопросы теории и методологии / В. Н. Самарина // Национальные интересы: приоритеты и безопасность. - 2015. - № 2 (287). С. 2-9.

Устойчивое развитие: новые вызовы : учебник для вузов / под общ. ред. В. И. Данилова-Данильяна, А. Н. Пискуловой. - М. : Проспект Пресс, 2015. - 336 c.

Шкиперова, Г. И. Анализ моделирования взаимосвязи между экономическим ростом и качеством окружающей среды (на примере Республики Карелия) / Г. И. Шкиперова // Экономический анализ: теория и практика. - 2014. № 43 (394). - С. 41-49.

Эколого-экономический индекс регионов РФ. Методика и показатели для расчета / С. Н. Бобылев [и др.]. - M. : WWF России, РИА Новости, 2015. - $152 \mathrm{c}$.

Яковлева, Е. Ю. Экономическая оценка межотраслевых потоков природных ресурсов и загрязнений : дис. ... канд. экон. наук : 08.00.05. - М., 2016. -169 c.

Яшалова, Н. Н. Анализ проявления эффекта декаплинга в эколого-экономической деятельности региона / Н. Н. Яшалова // Региональная экономика: теория и практика. - 2014. № 9 (366). - C. 54-60.

System of Environment-Ecomonic Accounting 2012 : Applications and Extensions (White cover publication / pre-edited text subject to official editing). - Eurorean Commission, FAO, OECD, United Natoins, World Bank, 2012.

\section{REFERENCES}

Akulov A.O. Effekt dekaplinga v industrialnom regione (na primere Kemerovskoy oblasti) [The Effect of Decoupling in the Industrial Region (On the Example of the Kemerovo Region)]. Ekonomicheskie i sotsialnye peremeny: fakty, tendentsii, prognoz [Economic and Social Changes: Facts, Trends, Forecast], 2013, no. 4(28), pp. 177-185.

Globalnyy zelenyy novyy kurs. Doklad, mart $2009 \mathrm{~g}$. Izdano Programmoy OON po okruzhayushchey srede $v$ ramkakh Initsiativy po zelenoy ekonomike [Global Green New Deal. Report, March 2009 Published by the United Nations Environment Program as Part of the Green Economy Initiative]. URL: http:// www.unepcom. ru/images/greeneconomy/ greennewdeal.pdf.

DumnovA.D., Boriskin D.A., Rybalskiy N.G. O nekotorykh metodakh makrostatisticheskogo analiza prirodopolzovaniya i okhrany okruzhayushchey sredy [About Some Methods of Macro-Statistical Analysis of Nature Management and Environmental Protection]. Vekglobalizatsii [Age of Globalization], 2017, no. 2, pp. 37-50.

Kirillov S.N., Pakina A.A., Tulskaya N.I. Otsenka ustoychivosti razvitiya na regionalnom urovne: primer Respubliki Tatarstan [Assessment of Sustainable Development at the Regional Level: An Example of the Republic of Tatarstan]. Vestnik Volgogradskogo gosudarstvennogo universiteta. Seriya 3, Ekonomika. Ekologiya [Science Journal of Volgograd State University. Global Economic System], 2017, no. 4, pp. 127-137. DOI: https://doi.org/10.15688/jvolsu3.2017.4.14.

Rezolyutsiya, prinyataya Generalnoy assamblei OON 25 sentyabrya $2015 \mathrm{~g}$. [Resolution Adopted by the UN General Assembly on September 25, 2015]. URL: https://undocs.org/ru/A/RES/70/1.

Samarina V.P. «Zelenaya» ekonomika Rossii: nekotorye voprosy teorii i metodologii ["Green" Economy of Russia: Some Issues of Theory and Methodology]. Natsionalnye interesy: prioritety $i$ bezopasnost [National Interests: Priorities and Security], 2015, no. 2 (287), pp. 2-9. 
Danilov-Danilyan V.I., Piskulova A.N., eds. Ustoychivoe razvitie: novye vyzovy: uchebnik dlya vuzov [Sustainable Development: New Challenges. Textbook for Institutes of Higher Education]. Moscow, Prospekt Press Publ., 2015. $336 \mathrm{p}$.

Shkiperova G.I. Analiz modelirovaniya vzaimosvyazi mezhdu ekonomicheskim rostom i kachestvom okruzhayushchey sredy (na primere Respubliki Kareliya) [Analysis of Modeling the Relationship Between Economic Growth and Environmental Quality (For Example, the Republic of Karelia)]. Ekonomicheskiy analiz: teoriya i praktika [Economic Analysis: Theory and Practice], 2014, no. 43 (394), pp. 41-49.

Bobylev S.N., Minakov V.S. et al. Ekologoekonomicheskiy indeks regionov RF. Metodika $i$ pokazateli dlya rascheta [Ecological and Economic Index of the Regions of the Russian Federation. Methodology and Indicators for
Calculation]. Moscow, WWF Rossii, RIA Novosti, 2015.152 p.

Yakovleva E.Yu. Ekonomicheskaya otsenka mezhotraslevykh potokov prirodnykh resursov $i$ zagryazneniy: dis. ... kand. ekon. nauk [Economic Assessment of Intersectoral Flows of Natural Resources and Pollution: Cand. econ. sci. diss.]. Moscow, 2016. 169 p.

Yashalova N.N. Analiz proyavleniya effekta dekaplinga v ekologo-ekonomicheskoy deyatelnosti regiona [Analysis of Manifestation of the Decoupling Effect in the Ecological and Economic Activity of the Region]. Regionalnaya ekonomika: teoriya i praktika [Regional Economics: Theory and Practice], 2014, no. 9 (366), pp. 54-60.

System of Environment-Ecomonic Accounting 2012: Applications and Extensions (White Cover Publication / Pre-Edited Text Subject to Official Editing). Eurorean Commission, FAO, OECD, United Natoins, World Bank, 2012.

\section{Information About the Authors}

Irina D. Anikina, Doctor of Sciences (Economics), Professor, Head of the Department of Economic Security and Accounting, Volgograd State University, Prosp. Universitetsky, 100, 400062 Volgograd, Russian Federation, anikina@volsu.ru, https://orcid.org/0000-0002-9535-5909

Andrey A. Anikin, Postgraduate Student, Department of Applied Mathematics and Mathematical Methods in Economics, Volgograd State University, Prosp. Universitetsky, 100, 400062 Volgograd, Russian Federation, theandnk@yahoo.com, https://orcid.org/0000-0002-6960-4158

\section{Информация об авторах}

Ирина Дмитриевна Аникина, доктор экономических наук, профессор, заведующая кафедрой экономической безопасности и бухгалтерского учета, Волгоградский государственный университет, просп. Университетский, 100, 400062 г. Волгоград, Российская Федерация, anikina@volsu.ru, https://orcid.org/0000-0002-9535-5909

Андрей Андреевич Аникин, аспирант кафедры прикладной математики и математических методов в экономике, Волгоградский государственный университет, просп. Университетский, 100, 400062 г. Волгоград, Российская Федерация, theandnk@yahoo.com, https://orcid.org/0000-0002-6960-4158 